\title{
Exercise testing in pulmonary arterial hypertension and in chronic heart failure
}

\author{
G. Deboeck*, G. Niset", M. Lamotte ${ }^{\#}$, J-L. Vachiéry", R. Naeije*
}

Exercise testing in pulmonary arterial hypertension and in chronic heart failure. G. Deboeck, G. Niset, M. Lamotte, J-L. Vachiéry, R. Naeije. (C)ES Journals Ltd 2004.

ABSTRACT: Exercise capacity is reduced in pulmonary arterial hypertension and in chronic left heart failure, but it is not known whether the cardiopulmonary exercise testing profile is different in the two conditions at the same severity of functional limitation.

Nineteen patients with pulmonary arterial hypertension and 19 with chronic heart failure underwent a 6-min walk test and symptom-limited maximal incremental cycle ergometry.

The patients with pulmonary arterial hypertension and chronic heart failure did not differ in New York Heart Association Functional Class (mean \pm SEM $2.8 \pm 0.1$ versus $2.8 \pm 0.2)$, 6-min walking distance $(395 \pm 30$ versus $419 \pm 20 \mathrm{~m})$, peak work-rate, oxygen consumption, ventilation and cardiac frequency. However, patients with pulmonary arterial hypertension exhibited higher dyspnoea scores $(5.8 \pm 0.6$ versus $3.8 \pm 0.5)$ higher ventilatory equivalents for carbon dioxide $(58 \pm 3$ versus $44 \pm 3$ at the anaerobic threshold) and lower peak oxygen pulse $\left(5.9 \pm 0.4\right.$ versus $8.7 \pm 0.5 \mathrm{~mL}^{- \text {beat }^{-1}}$, or $53 \pm 4$ versus $64 \pm 4 \%$ of the predicted value).

It is concluded that the cardiopulmonary exercise testing profile in pulmonary arterial hypertension differs from that in chronic heart failure by showing more dyspnoea at comparable work-rates, related to greater reductions in ventilatory efficiency and stroke volume.

Eur Respir J 2004; 23: 747-751.
*Dept of Physiology, Faculty of Medicine, and ${ }^{\#}$ Dept of Cardiology, Erasme Hospital, Free University of Brussels, Brussels, Belgium.

Correspondence: R. Naeije, Laboratory of Physiology, Erasmus Campus, CP 604, Route de Lennik 808, B-1070 Brussels, Belgium.

Fax: 3225554124

E-mail: rnaeije@ulb.ac.be

Keywords: Anaerobic threshold

chronic heart failure

exercise

oxygen consumption

pulmonary arterial hypertension

six-minute walk test

Received: October 72003

Accepted after revision: December 112003

This study was supported by grant number 3.4567.00 from the Scientific Medical Research Funds and by the Foundation for Cardiac Surgery (both Brussels, Belgium).
Primary pulmonary hypertension (PPH) is a disease entity of dyspnoea, fatigue, chest pain and syncope defined by an increase in pulmonary arterial pressures and the absence of causal cardiac or pulmonary disease [1]. The condition evolves over years, with prominent exercise-induced symptoms, due to the inability of the overloaded right ventricle to perfuse the lungs and to adapt systemic oxygen delivery to peripheral tissue oxygen demand. Accordingly, PPH patients present with reductions in peak oxygen uptake, anaerobic threshold, oxygen pulse, ventilatory efficiency and 6-min walking distance [2-7], which have been found to be correlated with New York Heart Association Functional Class (NYHAFC) and survival better than with resting pulmonary haemodynamic measurements [6, 7]. These concepts probably apply to pulmonary arterial hypertension (PAH) defined as PPH with identifiable associated conditions [8].

Chronic heart failure (CHF) is characterised by impairment of cardiac output adaptation to peripheral oxygen requirements, and also results in altered cardiopulmonary exercise testing variables and decreased 6-min walking distances, which correlate better with NYHAFC and prognosis than with resting invasive or noninvasive measurements of cardiac function [9-13].

It was, therefore, questioned what the differences in exercise testing variables in $\mathrm{CHF}$ and in $\mathrm{PAH}$ patients evaluated at the same severity of functional limitation might be. For this purpose, incremental cycle cardiopulmonary exercise testing and 6-min walking distance measurements were performed in PAH and CHF patients of comparable NYHAFC.
Methods

\section{Patients}

Thirty-eight patients were included in the study, which was approved by the Ethical Committee of Erasme University Hospital. Nineteen patients, 11 females and eight males, aged 23-66 yrs (mean 49 yrs), presented with PAH, defined by an increase in pulmonary artery pressures, normal pulmonary artery wedge pressure, no identifiable cardiac or pulmonary cause [1], and possibly association with conditions such as appetite suppressant intake, connective tissue disease, liver cirrhosis, human immunodeficiency virus infection and congenital left-to-right shunt [8]. Fifteen of the PAH patients had pure $\mathrm{PPH}$, and four $\mathrm{PPH}$ with associated conditions, which were previous intake of fenfluramines in two and connective tissue disease without significant lung function impairment in two. Absence of intrinsic left ventricular disease was checked by echocardiography. Six of the PAH patients were in NYHAFC II, 12 in NYHAFC III and one in NYHAFC IV. Nineteen patients, three females and 16 males, aged 50-70 yrs (mean $58 \mathrm{yrs}$ ), presented with $\mathrm{CHF}$, defined by the syndrome of dyspnoea, fatigue and oedema related to altered left ventricular function, with echocardiographic left ventricular ejection fractions ranging 14-45\% (mean \pm SEM $27 \pm 11 \%$ ). The cause of left ventricular failure was ischaemic cardiomyopathy in 13 of the patients and dilated idiopathic cardiomyopathy in the others. Seven of the CHF patients 
were in NYHAFC II, eight in NYHAFC III and four in NYHAFC IV.

Patients were included in the study if: 1) they had been clinically stable during the preceding month, 2) they were in NYHAFC II, III or IV, and 3) they were able to perform cycle ergometer exercise testing. The inclusions were consecutive, and with prior knowledge that approximately twothirds of the patients would be in NYHAFC III and the others in NYHAFC II, resulting in a mean 6-min walking distance of $\sim 400 \mathrm{~m}$.

Right heart catheterisation had been performed during the preceding month in 24 of the patients. In the PAH patients $(\mathrm{n}=17)$, mean pulmonary artery pressure was $47 \pm 3 \mathrm{mmHg}$, pulmonary artery wedge pressure $11 \pm 2 \mathrm{mmHg}$ and cardiac index $2.1 \pm 0.1 \mathrm{~L} \cdot \mathrm{min}^{-1} \cdot \mathrm{m}^{-2}$. In the CHF patients $(\mathrm{n}=7)$, mean pulmonary artery pressure was $32 \pm 6 \mathrm{mmHg}$, pulmonary artery wedge pressure $23 \pm 4 \mathrm{mmHg}$ and cardiac index $1.9 \pm 0.2 \mathrm{~L} \cdot \mathrm{min}^{-1} \cdot \mathrm{m}^{-2}$. Three of the PAH patients showed echocardiographic evidence of a patent foramen ovale and right-to-left shunting.

The PAH patients were treated with anticoagulants $(n=19)$; calcium channel blockers $(n=5)$; diuretics $(n=15)$; oral, subcutaneous or intravenous prostacyclin derivatives $(n=14)$; and the mixed endothelin receptor antagonist bosentan $(n=2)$. The CHF patients were treated with diuretics $(n=17)$, angiotensin-converting enzyme inhibitors or angiotensin II receptor antagonists $(n=14), \beta$-blockers $(n=16)$ and nitrates $(\mathrm{n}=10)$.

\section{Six-minute walk test}

Measurement of the distance walked in 6 min was performed in all the patients according to a standardised protocol [14]. The patients were instructed to walk back and forth at their own pace in a $35-\mathrm{m}$ corridor in order to cover as much ground as possible in the allotted time. A research assistant supervised the test, telling the patient the remaining exercise time every $2 \mathrm{~min}$. The patients were allowed to stop and take a rest during the test, but were instructed to resume walking as soon as possible. In order to control for the learning effect, each patient underwent at least two tests on at least two separate days, and the final performance was used as the measure of walking ability. Pulse oximetric arterial oxygen saturation $\left(\mathrm{Sp}, \mathrm{O}_{2}\right)$ was measured using a Nonin $8500 \mathrm{M}$ device (Nonin Medical, Minneapolis, MN, USA). Dyspnoea during the test was evaluated using the modified Borg dyspnoea score [15].

\section{Cardiopulmonary exercise test}

Each patient underwent physician-supervised standard incremental cardiopulmonary exercise testing until the symptom-limited maximum [16]. The work-rate was increased by $10 \mathrm{~W} \cdot \mathrm{min}^{-1}$, after pedalling for $1 \mathrm{~min}$ at $0 \mathrm{~W}$. The patients were instructed to stop exercising immediately if they felt dizziness or chest pain. Breath-by-breath ventilation, oxygen and carbon dioxide concentrations, and the derived minute ventilation, oxygen consumption $\left(V^{\prime} \mathrm{O}_{2}\right)$ and carbon dioxide production $\left(V^{\prime} \mathrm{CO}_{2}\right)$ were determined using the Cardiopulmonary Exercise System CPX/D (Medical Graphics, St Paul, MN, USA). Cardiac frequency was measured using a continuously monitored electrocardiograph. Blood pressure was measured at the end of each workload increment using an automatic sphygmomanometer. Peak $V^{\prime} \mathrm{O}_{2}$ was defined as the $V^{\prime} \mathrm{O}_{2}$ measured during the last $30 \mathrm{~s}$ of peak exercise. Oxygen pulse was calculated by dividing $V^{\prime} \mathrm{O}_{2}$ by cardiac frequency.
The anaerobic threshold was detected using the V-slope method [16]. The ventilatory equivalent for carbon dioxide was measured by dividing ventilation by $V^{\prime} \mathrm{CO}_{2}$ at baseline, at the anaerobic threshold and at peak $V^{\prime} \mathrm{O}_{2}$. Work efficiency above the anaerobic threshold was calculated by the ratio of change in $V^{\prime} \mathrm{O}_{2}$ per unit increase in work-rate $\left(\Delta V^{\prime} \mathrm{O}_{2} / \Delta\right.$ workrate) [16].

\section{Statistics}

Data are presented as mean \pm SEM. Comparisons between the PAH and CHF groups were made by unpaired t-test. Correlations were calculated using linear regression analysis [17].

\section{Results}

The CHF patients were older than the PAH patients, and were more often male, but the two groups were otherwise well matched in height, weight, resting cardiac frequency, blood pressure, NYHAFC and 6-min walking distance. The PAH patients exhibited a slightly but significantly lower $S \mathrm{p}, \mathrm{O}_{2}$ at rest and exercise-induced hypoxaemia (table 1).

As summarised in table 2, both $\mathrm{PAH}$ and $\mathrm{CHF}$ patients presented with lower-than-normal work-rate, $V^{\prime} \mathrm{O}_{2}$, oxygen pulse, ventilation and cardiac frequency at peak exercise. Both PAH and CHF patients also had a lower-than-normal anaerobic threshold (absolute or percentage of the predicted value), $\Delta V^{\prime} \mathrm{O}_{2} / \Delta$ work-rate above the anaerobic threshold and cardiac frequency recovery. The peak respiratory exchange rate was within the limits of normal. Resting ventilation, anaerobic threshold (expressed as a percentage of peak $V^{\prime} \mathrm{O}_{2}$ ) and ventilatory equivalents were higher than normal.

The PAH and CHF patients did not differ in work-rate (\% pred), peak $V^{\prime} \mathrm{O}_{2}$ (\% pred), anaerobic threshold, peak respiratory exchange rate, peak ventilation, peak cardiac frequency and cardiac frequency recovery. However, CHF patients achieved higher absolute peak work-rate and peak $V^{\prime} \mathrm{O}_{2}$, and $\mathrm{PAH}$ patients showed higher dyspnoea scores, ventilation and ventilatory equivalents, and lower maximum oxygen pulse and $\Delta V^{\prime} \mathrm{O}_{2} / \Delta$ work-rate above the anaerobic threshold. Ventilatory equivalents were on average higher in PAH patients at rest, at the anaerobic threshold and at peak

Table 1.-Anthropometric data and functional state of pulmonary arterial hypertension (PAH) and chronic heart failure (CHF) patients

\begin{tabular}{lccc}
\hline & PAH & CHF & p-value \\
\hline Patients n & 19 & 19 & \\
Age yrs & $49 \pm 3$ & $58 \pm 1$ & $<0.01$ \\
Height cm & $170 \pm 2$ & $171 \pm 2$ & $\mathrm{NS}$ \\
Weight kg & $76 \pm 3$ & $78 \pm 4$ & $\mathrm{NS}$ \\
Cardiac frequency beats· $\mathrm{min}^{-1}$ & $78 \pm 22$ & $75 \pm 14$ & $\mathrm{NS}$ \\
BPsys mmHg & $113 \pm 26$ & $113 \pm 18$ & $\mathrm{NS}$ \\
BPdias mmHg & $71 \pm 10$ & $67 \pm 10$ & $\mathrm{NS}$ \\
NYHAFC & $2.7 \pm 0.1$ & $2.8 \pm 0.2$ & $\mathrm{NS}$ \\
6-min walking distance m & $395 \pm 30$ & $419 \pm 20$ & $\mathrm{NS}$ \\
Sp, $\mathrm{O}_{2} \%$ & & & \\
$\quad$ Resting & $94 \pm 1$ & $97 \pm 2$ & $<0.001$ \\
Peak exercise & $86 \pm 2$ & $96 \pm 3$ & $<0.003$ \\
Borg score & $5.8 \pm 0.6$ & $3.8 \pm 0.5$ & $<0.02$ \\
\hline
\end{tabular}

BPsys: systolic blood pressure; BPdias: diastolic blood pressure; NYHAFC: New York Heart Association Functional Class; $\mathrm{Sp}, \mathrm{O}_{2}$ : arterial oxygen saturation measured by pulse oximetry. NS: nonsignificant. 
Table 2.-Cardiopulmonary exercise testing variables in pulmonary arterial hypertension (PAH) and chronic heart failure (CHF) patients

\begin{tabular}{|c|c|c|c|c|}
\hline & PAH & $\mathrm{CHF}$ & p-value & $\begin{array}{l}\text { Normal } \\
\text { limits }\end{array}$ \\
\hline Peak WR W & $53 \pm 5$ & $73 \pm 6$ & $<0.05$ & $129-241$ \\
\hline$\%$ pred & $36 \pm 4$ & $42 \pm 3$ & NS & $80-120$ \\
\hline Peak $V^{\prime} \mathrm{O}_{2} \mathrm{~mL} \cdot \mathrm{kg}^{-1} \cdot \mathrm{min}^{-1}$ & $10.1 \pm 0.6$ & $12.8 \pm 0.8$ & $<0.01$ & $23-32$ \\
\hline$\%$ pred & $40 \pm 3$ & $44 \pm 3$ & NS & $80-120$ \\
\hline AT $\mathrm{mL} \cdot \mathrm{kg}^{-1} \cdot \mathrm{min}^{-1}$ & $7.9 \pm 0.5$ & $9.2 \pm 0.6$ & NS & $12-17$ \\
\hline$\%$ pred & $57 \pm 4$ & $58 \pm 3$ & NS & $80-120$ \\
\hline$\%$ peak $V^{\prime} \mathrm{O}_{2}$ & $74 \pm 3$ & $71 \pm 3$ & NS & $45-65$ \\
\hline$\%$ pred peak $V^{\prime} \mathrm{O}_{2}$ & $31 \pm 2$ & $32 \pm 2$ & NS & \\
\hline Peak $\mathrm{O}_{2}$ pulse $\mathrm{mL} \cdot$ beat $^{-1}$ & $5.9 \pm 0.4$ & $8.7 \pm 0.5$ & $<0.001$ & $9.1-16.5$ \\
\hline$\%$ pred & $53 \pm 4$ & $64 \pm 4$ & $<0.05$ & $80-120$ \\
\hline Peak RER & $1.15 \pm 0.02$ & $1.19 \pm 0.02$ & NS & $1.15-1.25$ \\
\hline \multicolumn{5}{|l|}{$V^{\prime} \mathrm{E} \mathrm{L} \cdot \mathrm{min}^{-1}$} \\
\hline Resting & $14.3 \pm 1.0$ & $11.4 \pm 0.8$ & $<0.03$ & $4.8-7.2$ \\
\hline Peak & $55 \pm 5$ & $55 \pm 3$ & NS & 70-108 \\
\hline Peak $f_{\mathrm{c}}$ beats $\cdot \mathrm{min}^{-1}$ & $131 \pm 5$ & $115 \pm 5$ & 0.06 & $150-178$ \\
\hline \multicolumn{5}{|l|}{$V^{\prime} \mathrm{E} / V^{\prime} \mathrm{CO}_{2}$} \\
\hline Resting & $59 \pm 2$ & $49 \pm 3$ & $<0.01$ & $33-35$ \\
\hline AT & $58 \pm 3$ & $44 \pm 3$ & $<0.01$ & $26-30$ \\
\hline Peak & $69 \pm 4$ & $48 \pm 3$ & $<0.001$ & $35-40$ \\
\hline $\begin{array}{l}\Delta V^{\prime} \mathrm{O}_{2} / \Delta \mathrm{WR} \text { above } \mathrm{AT} \\
\mathrm{mL} \cdot \mathrm{min}^{-1} \cdot \mathrm{W}^{-1}\end{array}$ & $5.3 \pm 2.3$ & $8.4 \pm 3.8$ & $<0.02$ & $9-11$ \\
\hline$f_{\mathrm{c}}$ recovery beats $\cdot \mathrm{min}^{-1}$ & $11 \pm 2$ & $10 \pm 2$ & NS & $>12$ \\
\hline
\end{tabular}

WR: work-rate; $V^{\prime} \mathrm{O}_{2}$ : oxygen consumption; AT: anaerobic threshold; RER: respiratory exchange rate; $V^{\prime} \mathrm{E}$ : ventilation; $f_{\mathrm{c}}$ : cardiac frequency; $V^{\prime} \mathrm{CO}_{2}$ : carbon dioxide production; $\Delta V^{\prime} \mathrm{O}_{2} / \Delta \mathrm{WR}$ : change in $V^{\prime} \mathrm{O}_{2}$ per unit increase in WR; $f_{\mathrm{c}}$ recovery: decrease in $f_{\mathrm{c}} 1 \mathrm{~min}$ after peak exercise (lower limit of normal from [18]); \% pred: per cent predicted. NS: nonsignificant.

$V^{\prime} \mathrm{O}_{2}$ (fig. 1). Marked decreases in peak oxygen pulse were observed in both PAH and CHF patients (fig. 2).

The 6-min walking distance correlated with peak $V^{\prime} \mathrm{O}_{2}$, NYHAFC, peak work-rate and ventilatory equivalents in both PAH and CHF patients (table 3). The 6-min walking distance correlated less consistently with the anaerobic threshold, depending on whether it was expressed in absolute terms or relative to peak $V^{\prime} \mathrm{O}_{2}$, and correlated with peak oxygen pulse in $\mathrm{PAH}$ but not $\mathrm{CHF}$ patients.

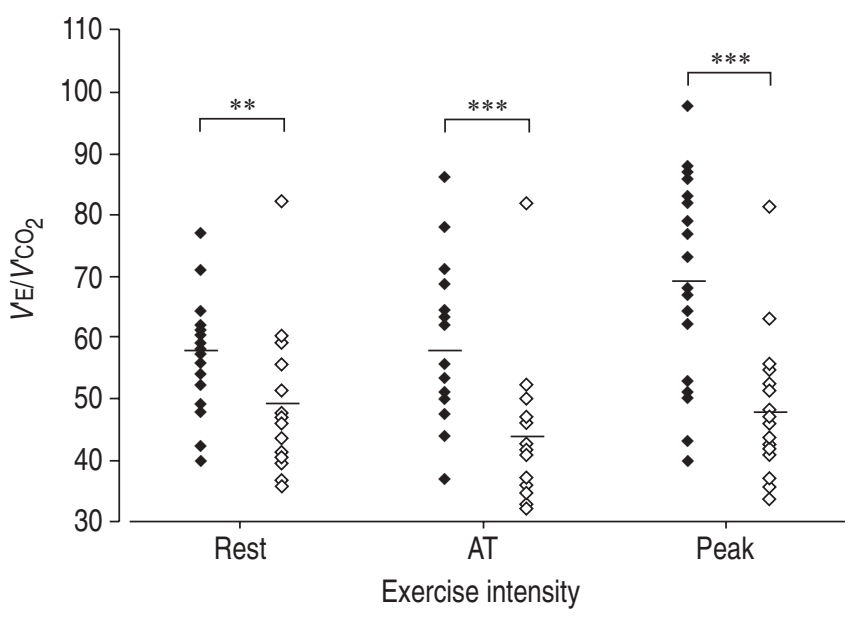

Fig. 1.- Ventilatory equivalent for carbon dioxide $\left(V^{\prime} \mathrm{E} / V^{\prime} \mathrm{CO}_{2}\right)$ at rest, at the anaerobic threshold (AT) and at maximal (peak) exercise intensity in patients with pulmonary arterial hypertension (PAH; and in patients with chronic heart failure $(\mathrm{CHF} ; \diamond)$. Horizontal bars represent means. ${ }^{* *}: \mathrm{p}<0.01 ; * * *: \mathrm{p}<0.001$.

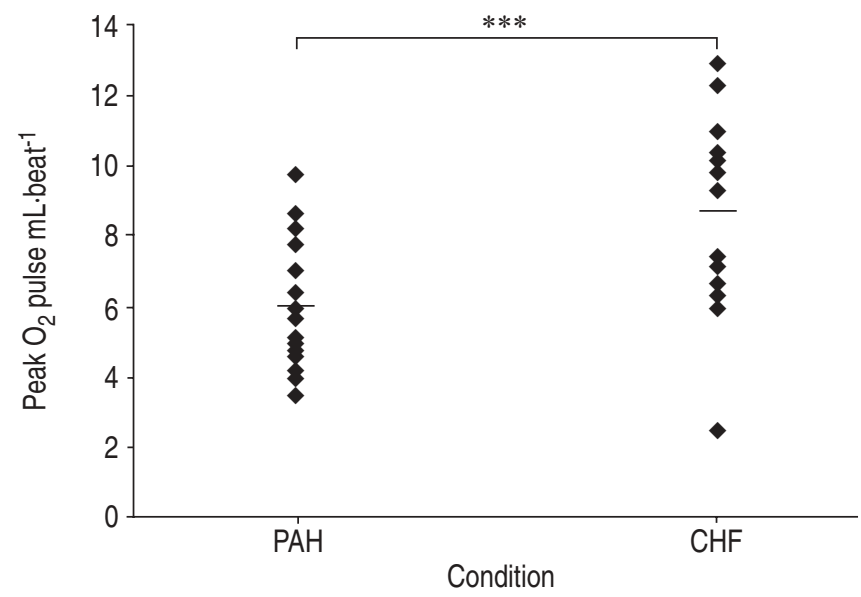

Fig. 2.-Peak oxygen pulse in patients with pulmonary arterial hypertension $(\mathrm{PAH})$ and in patients with chronic heart failure $(\mathrm{CHF})$. Horizontal bars represent means. $* * *: \mathrm{p}<0.001$.

\section{Discussion}

The present results reveal that cardiopulmonary exercise testing in PAH and CHF patients at the same functional capacity, as graded by NYHAFC and distance walked in 6 min, shows similarly reduced peak work-rate and $V^{\prime} \mathrm{O}_{2}$, with an early anaerobic threshold, and increased ventilatory equivalents. However, at a given level of exercise, the PAH patients appear to be more dyspnoeic in relation to more reduced ventilatory efficiency and stroke volume as assessed by higher ventilatory equivalent for carbon dioxide and lower oxygen pulse.

Previous studies have shown that advanced PAH and CHF are both characterised by decreased peak work-rate, peak $V^{\prime} \mathrm{O}_{2}, V^{\prime} \mathrm{O}_{2}$ at the anaerobic threshold and peak oxygen pulse, and increased ventilatory equivalents [2-7, 9-13]. In the present patients, the anaerobic threshold occurred at a higher percentage of peak $V^{\prime} \mathrm{O}_{2}$ than in normal subjects. This has been previously noted in PPH [4], CHF [19] and older patients with various diseases associated with a decrease in peak $V^{\prime} \mathrm{O}_{2}$

Table 3. - Correlation coefficients for the relationship between the 6-min walking distance and cardiopulmonary exercise test variables in pulmonary arterial hypertension (PAH) and chronic heart failure (CHF) patients

\begin{tabular}{|c|c|c|}
\hline & PAH & $\mathrm{CHF}$ \\
\hline Peak WR W & $0.72 * * *$ & $0.66^{* * *}$ \\
\hline$\%$ pred & $0.61 * * *$ & $0.57 *$ \\
\hline Peak $V^{\prime} \mathrm{O}_{2} \mathrm{~mL} \cdot \mathrm{kg}^{-1} \cdot \mathrm{min}^{-1}$ & $0.62 * * *$ & $0.64 * * *$ \\
\hline$\%$ pred & $0.65^{* * *}$ & $0.45^{* *}$ \\
\hline AT $\mathrm{mL} \cdot \mathrm{kg}^{-1} \cdot \mathrm{min}^{-1}$ & $0.60 * * *$ & 0.17 \\
\hline$\%$ peak $V^{\prime} \mathrm{O}_{2}$ & $-0.42^{*}$ & $-0.65 * * *$ \\
\hline NYHAFC & $-0.51^{* *}$ & $-0.55^{* *}$ \\
\hline Peak $\mathrm{O}_{2}$ pulse $\mathrm{mL} \cdot$ beat $^{-1}$ & $0.47 * *$ & 0.24 \\
\hline \multicolumn{3}{|l|}{$V^{\prime} \mathrm{E} / V^{\prime} \mathrm{CO}_{2}$} \\
\hline Resting & $-0.5^{* *}$ & $-0.64 * * *$ \\
\hline AT & $-0.51 * *$ & $-0.64 * * *$ \\
\hline Peak & $-0.51 * *$ & $-0.56^{* * *}$ \\
\hline$\Delta V^{\prime} \mathrm{O}_{2} / \Delta \mathrm{WR}$ above $\mathrm{AT} \mathrm{mL} \cdot \mathrm{min}^{-1} \cdot \mathrm{W}^{-1}$ & 0.45 & 0.21 \\
\hline Peak $f_{\mathrm{c}}$ beats $\cdot \min ^{-1}$ & $0.43^{*}$ & $0.5^{* *}$ \\
\hline
\end{tabular}

WR: work-rate; $V^{\prime} \mathrm{O}_{2}$ : oxygen consumption; AT: anaerobic threshold; NYHAFC: New York Heart Association Functional Class; $V^{\prime} \mathrm{E}$ : ventilation; $V^{\prime} \mathrm{CO}_{2}$ : carbon dioxide production; $\Delta V^{\prime} \mathrm{O}_{2} / \Delta \mathrm{WR}$ : change in $V^{\prime} \mathrm{O}_{2}$ per unit increase in WR; $f$ c: cardiac frequency; $\%$ pred: per cent predicted. *: $\mathrm{p}<0.05 ; * *$ : $\mathrm{p}<0.01 ; * * *: \mathrm{p}<0.001$. 
[20]. It may be explained by the slower rise in $V^{\prime} \mathrm{O}_{2}$ above the anaerobic threshold and by the fact that resting $V^{\prime} \mathrm{O}_{2}$ already represents a considerable proportion of peak $V^{\prime} \mathrm{O}_{2}$ [4]. It is also possible that, in these patients, many daily activities are frequently performed above the anaerobic threshold, with a corresponding endurance training effect.

Both the PAH and $\mathrm{CHF}$ patients presented with a decreased $V^{\prime} \mathrm{O}_{2}$ /work-rate relationship above the anaerobic threshold. This effect, which was more pronounced in the PAH patients, has been previously reported in patients with ischaemic heart disease [21] and PPH [4]. This may be explained by cardiac output limitation, as also suggested by marked decreases in peak oxygen pulse and peak cardiac frequency in the present patients. An alteration in peripheral tissue oxygen extraction is less likely, since very low mixed venous blood oxygenation during exercise is known to occur in both PPH and CHF.

A decreased chronotropic response was observed in both the PAH and $\mathrm{CHF}$ patients. Although this is classically described in CHF [22], it has only been reported in one other study on $\mathrm{PPH}$ patients [4]. Chronotropic incompetence in $\mathrm{CHF}$ is believed to be due to downregulation of $\beta$ adrenoreceptors [22]. The same explanation may hold true in $\mathrm{PAH}$ patients, in whom downregulation of right ventricular myocardial $\beta$-adrenoreceptors has also been reported [23]. It should, however, be noted that the decrease in chronotropic response appeared less important in the present PAH patients $(\mathrm{p}=0.06)$. This may be related to an additional contribution of $\beta$-blocker therapy in 16 of the $19 \mathrm{CHF}$ patients.

Abnormal cardiac frequency recovery immediately after completion of an exercise test has recently been shown by several studies to be associated with decreased survival in patients with coronary artery disease, with or without $\beta$-blocker therapy, and whether or not the exercise is followed by a cooling-down period [18]. The limits of normal postexercise cardiac frequency recovery remain somewhat arbitrary as 12 beats $\cdot \min ^{-1}$ [18] and even 18 beats $\cdot \min ^{-1}$ [24] have been proposed. In the face of these limits of normal, it appears that both the present $\mathrm{PAH}$ and $\mathrm{CHF}$ patients frequently exhibited an abnormally prolonged cardiac frequency recovery. The mechanisms of prolonged cardiac frequency recovery after exercise in cardiac patients remain incompletely understood [13].

In the present study, the peak oxygen pulse was lower in PAH than in CHF patients, with a tendency towards higher peak cardiac frequency. This could account for the relatively lower absolute value of peak $V^{\prime} \mathrm{O}_{2}$ due to inability to increase cardiac output, as also suggested by the lower $\Delta V^{\prime} \mathrm{O}_{2} / \Delta$ workrate above the anaerobic threshold. In PAH, the excessively afterloaded right ventricle may partially adapt by a relative decrease in stroke volume at a given mean flow output, which decreases the pulsatile component of ventricular hydraulic work [25]. However, $\beta$-blocker therapy in $\mathrm{CHF}$ patients could also explain the relatively larger oxygen pulses.

Although absolute values of peak $V^{\prime} \mathrm{O}_{2}$ and work-rate were higher in the $\mathrm{CHF}$ patients, peak $V^{\prime} \mathrm{O}_{2}$ and work-rate expressed as a percentage of the predicted value were not different in the two study groups. This may, in part, be explained by the fact that the prediction equations include sex corrections. It is known that, everything else being equal, $V^{\prime} \mathrm{O}_{2}$ and work-rate achieved are lower in females [16]. Peak oxygen pulse is also lower in females [16], but remained lower when expressed as a percentage of the predicted value in the PAH compared to the CHF patients in the current study. The sex distributions in the present $\mathrm{PAH}$ and $\mathrm{CHF}$ groups were typical of these respective disease entities, with relatively more females and males respectively.

Peak ventilation was markedly decreased in both the PAH and $\mathrm{CHF}$ patients. However, ventilatory equivalents were abnormally increased, and this was more pronounced in the PAH patients. An increased ventilatory equivalent is a marker of poor prognosis in both PPH [6] and CHF [11]. Increased ventilatory equivalents at exercise in $\mathrm{CHF}$ have been explained by a combination of increased dead space related to low cardiac output, early lactic acidosis [9] and increased chemosensitivity in the context of increased sympathetic nervous system tone [26]. Additional factors in PAH could include a greater increase in physiological dead space because of pulmonary vascular obliteration, and hypoxaemia on right-to-left shunting through a patent foramen ovale [2-5, 27]. The present $\mathrm{PAH}$ patients exhibited a slightly lower $\mathrm{Sp}, \mathrm{O}_{2}$ at rest, and presented with exercise-induced hypoxaemia, which probably contributed to increase ventilatory equivalents and dyspnoea score. An increase in physiological dead space is a probable explanation. Previous studies on pulmonary gas exchange using the multiple inert gas elimination technique in patients with either primary or thromboembolic pulmonary hypertension showed only mild ventilation/perfusion $\left(V^{\prime} / Q^{\prime}\right)$ inequality limited to lower-than-normal- $V^{\prime} / Q^{\prime}$ regions, with no high $V^{\prime} / Q^{\prime}$ modes and no increase in dead space [27-29]. Exercise, in these studies, did not alter $V^{\prime} / Q^{\prime}$ distributions, and, in particular, was shown not to be associated with an abnormal increase in dead space [29].

The 6-min walk test is a submaximal exercise test that is frequently used to assess the functional status of cardiac and pulmonary patients. It is safe, easy to perform, inexpensive, highly reproducible, sensitive to therapeutic interventions and gives a good indication of the ability to perform daily life activities [30]. Being a submaximal exercise test, the results correlated moderately with peak $V^{\prime} \mathrm{O}_{2}$ and other cardiopulmonary exercise testing variables. The correlation coefficients for the relationship between the 6-min walking distance and peak $V^{\prime} \mathrm{O}_{2}$ range $0.51-0.71$ in CHF [30], and have been reported to amount to 0.7 in $\mathrm{PPH}$ [7]. Similar correlations were found in the present study. It must be emphasised that the 6-min walk test did not appear to discriminate between $\mathrm{PAH}$ and $\mathrm{CHF}$ patients of the same functional class who presented with marked differences in cardiorespiratory adaptation to exercise pathophysiology that were disclosed by cardiopulmonary exercise testing.

In summary, pulmonary arterial hypertension patients exercise with relatively higher ventilatory equivalents and lower oxygen pulses than CHF patients, but otherwise present with similarly altered cardiopulmonary exercise test results. These differences might be explained by both relatively more altered right ventricular function and altered gas exchange in the high ventilation/perfusion regions of the lung, but more altered autonomic nervous system tone could also be involved.

Acknowledgements. M-T. Gautier and P. Jespers helped in the preparation of this report.

\section{References}

1. Rubin LJ. Primary pulmonary hypertension. $N$ Engl J Med 1997; 336: 111-117.

2. D'Alonzo GE, Gianotti LA, Pohil RL, et al. Comparison of progressive exercise performance of normal subjects and patients with primary pulmonary hypertension. Chest 1987; 92: 57-62.

3. Rhodes J, Barst RJ, Garofano RP, Thoele DG, Gersony WM. Hemodynamic correlates of exercise function in patients with primary pulmonary hypertension. J Am Coll Cardiol 1991; 18: $1738-1744$.

4. Riley MS, Porszasz J. Engelen MPKJ, Brundage BH, 
Wasserman K. Gas exchange responses to continuous incremental cycle ergometry exercise in primary pulmonary hypertension in humans. Eur J Appl Physiol 2000; 83: 63-70.

5. Sun XG, Hansen EJ, Oudiz R, Wasserman K. Exercise pathophysiology in patients with primary pulmonary hypertension. Circulation 2001; 104: 429-435.

6. Wensel R, Opitz CF, Anker SD, et al. Assessment of survival in patients with primary pulmonary hypertension. Importance of cardiopulmonary exercise testing. Circulation 2002; 106: $319-324$

7. Miyamoto S, Nagaya N, Satoh $\mathrm{T}$, et al. Clinical correlates and prognostic significance of 6-minute walk test in patients with pulmonary hypertension. Comparison with cardiopulmonary exercise testing. Am J Respir Crit Care Med 2000; 161: 487-492.

8. Fishman AP. Clinical classification of pulmonary hypertension. Clin Chest Med 2001; 22: 385-391.

9. Wasserman K, Zhang Y, Gitt A, et al. Lung function and exercise gas exchange in chronic heart failure. Circulation 1997; 96: 2221-2227.

10. Myers J, Gullestad L, Vagelos R, et al. Clinical, hemodynamic, and cardiopulmonary exercise test determinants of survival in patients referred for evaluation of heart failure. Ann Intern Med 1998; 129: 286-293.

11. Chua TP, Ponokowski P, Harrington D, et al. Clinical correlates and prognostic significance of the ventilatory response to exercise in chronic heart failure. $\mathrm{J} \mathrm{Am}$ Coll Cardiol 1997; 29: 1585-1590.

12. Cahalin LP, Mathier MA, Semigran MJ, Dec GW, DiSalvo TG. The six-minute walk test predicts peak oxygen uptake and survival in patients with advanced heart failure. Chest 1996; 110: 325-332.

13. Roul G, Germain P, Bareiss P. Does the 6-minute walk test predict the prognosis in patients with NYHA class II or III chronic heart failure? Am Heart $J$ 1998; 136: 449-457.

14. Guyatt GH, Sullivan MJ, Thompson PJ, et al. The sixminute walk: a new measure of exercise capacity in patients with chronic heart failure. Can Med Assoc J 1985; 132: 919923.

15. Borg GA. Psychophysical bases of perceived exertion. Med Sci Sports Exerc 1982; 14: 377-381.

16. Wasserman K, Hansen JE, Sue DY, Whipp BJ. Principles of Exercise Testing and Interpretation. 3rd Edn. Baltimore, MD, Lippincott Williams \& Wilkins, 1999; pp. 143-164.

17. Winer BJ. Statistical Principles in Experimental Design. New York, NY, McGraw-Hill, 1971.
18. Gibbons RJ. Abnormal heart rate recovery after exercise. Lancet 2002; 359: 1036-1037.

19. Matsumara N, Nishijima H, Kojima S, Hashimoto F, Minami M, Yasuda H. Determination of anaerobic threshold for assessment of functional status in patients with chronic heart failure. Circulation 1983; 68: 360-367.

20. Riley M, Maehara K, Porszasz J, Engelen MP, Brundage B, Wasserman K. Association between the anaerobic threshold and the break-point in the double product/work rate relationship. Eur J Appl Physiol 1997; 75: 14-21.

21. Hansen JE, Sue DY, Oren A, Wasserman K. Relation of oxygen uptake to work rate in normal men and men with circulatory disorders. Am J Cardiol 1987; 59: 669-674.

22. Colucci WS, Ribeiro JP, Rocco MB, et al. Impaired chronotropic response to exercise in patients with congestive heart failure. Role of post-synaptic $\beta$-adrenergic desensitization. Circulation 1979; 80: 314-323.

23. Bristow MR, Minobe W, Rasmussen R, et al. $\beta$-adrenergic neuroeffector abnormalities in the failing human heart are produced by local rather than systemic mechanisms. J Clin Invest 1992; 89: 803-815.

24. Watanabe J, Thamilarasan M, Blackstone EH, Thomas JD, Lauer MS. Heart rate recovery immediately after treadmill exercise and left ventricular systolic dysfunction as predictors of mortality: the case of stress echocardiography. Circulation 2001; 104: 1911-1916.

25. Nichols WW, O'Rourke MF. McDonald's Blood Flow in Arteries. 4th Edn. London, Edward Arnold, 1998.

26. Johnson RL. Gas exchange efficiency in congestive heart failure II. Circulation 2001; 103: 916-918.

27. Dantzker DR, Bower JS. Mechanisms of gas exchange abnormality in patients with chronic obliterative pulmonary vascular disease. J Clin Invest 1979; 64: 1050-1055.

28. Melot C, Naeije R, Mols P, Vandenbossche JL, Denolin H. Effects of nifedipine on ventilation/perfusion matching in primary pulmonary hypertension. Chest 1983; 83: 201207.

29. Dantzker DR, D'Alonzo GE, Bower JS, Popat K, Crevey BJ. Pulmonary gas exchange during exercise in patients with obliterative pulmonary hypertension. Am Rev Respir Dis 1984; 130: 412-416.

30. Fleg JL, Pina IL, Balady GJ, et al. Assessment of functional capacity in clinical and research applications: an advisory from the Committee on Exercise, Rehabilitation, and Prevention, Council on Clinical Cardiology, American Heart Association. Circulation 2000; 102: 1591-1597. 